\title{
IMPLEMENTASI TASAWUF DALAM PENDIDIKAN AGAMA ISLAM: INDEPENDENSI, DIALOG DAN INTEGRASI
}

\section{TASAWUF IMPLEMENTATION IN ISLAMIC EDUCATION: INDEPENDENCE, DIALOGUE AND INTEGRATION}

\author{
Bahar Agus Setiawan \\ Universitas Muhammadiyah Jember, Indonesia \\ Email: baharsetiawan@unmuhjember.ac.id \\ Benny Prasetiya \\ Sekolah Tinggi Agama Islam Muhammadiyah Probolinggo, Indonesia \\ Email: prasetiyabenny@gmail.com \\ Sofyan Rofi \\ Universitas Muhammadiyah Jember, Indonesia \\ Email: sofyan.rofi@unmuhjember.ac.id
}

\begin{abstract}
Abstrak
Tulisan ini bertujuan untuk mengemukakan implementasi tasawuf dalam pembelajaran pendidikan agama Islam yang dianalisis dengan pendekatan independensi, dialog, dan integrasi. Pembahasan ini menemukan bahwa pendidikan Islam di era globalisasi menjadi momentum dalam mengembangkan dan membangun pendidikan Islam yang kompetitif. Pendidikan Islam harus mampu menghadapi segala bentuk tantangan globalisasi dengan berbagai dampaknya. Kehadiran tasawuf menjadi penawar problematika pendidikan Islam yang sedang dihadapi. Terbentukknya insan kamil dari proses pendidikan agama Islam menjadikan tasawuf sebagai sebuah metode dan strategi pembelajaran.
\end{abstract}

Kata Kunci: independensi, integrasi, pendidikan agama Islam, tasawuf

\begin{abstract}
This paper aims to put forward the implementation of sufism (tasawuf) in the learning of Islamic education which is analyzed by the approach of independence, dialogue, and integration. This discussion finds that Islamic education in the era of globalization is momentum in developing and building competitive Islamic education. Islamic education must be able to face all forms of globalization challenges with their various impacts. The presence of Sufism is the antidote to the problem of the Islamic education being faced. The formation of our human beings from the process of Islamic education made Sufism a method and learning strategy.
\end{abstract}

Keywords: independence, integration, Islamic education, sufism 
Bahar Agus Setiawan, Benny Prasetiya, Sofyan Rofi: Implementasi Tasawuf dalam Pendidikan Agama Islam: Independensi, Dialog, dan Integrasi

\section{A. Pendahuluan}

Problematika pendidikan baik pendidikan umum maupun pendidikan agama Islam tidak akan punah dan sirna. Realitas empirik ini tidak bisa lepas atas konseptualisasi pendidikan yang bersifat dinamis, progresif dan kreatif tidak hanya pada aspek materi, kurikulum, model, metode dalam proses pembelajaran tetapi juga pada paradigma, pendekatan dan manusianya sendiri sebagai objek dan subjek pendidikan. Merujuk pada kalimat filosof Yunani Heracletos (540-480 S.M.) nothing endures but change, pendidikan Islam harus mampu berevolusi secara dinamis, kreatif dan inovatif bersifat komprehensif. Pendidikan Islam harus dimaknai pada konsepsi minimalismaksimalis yang membentuknya yaitu tarbiyyah (pengasuhan), ta'lim (belajar) dan ta'dib (kebaikan/keadaban). ${ }^{1}$

Pemahaman terhadap pendidikan Islam harus merujuk pada tiga pengertian, yaitu: pertama, pendidikan Islam sebagai institusi; kedua, sebagai mata pelajaran/bidang studi; dan ketiga, sebagai nilai (value). Berkaitan dengan definisi tersebut, istilah pendidikan Islam dan pendidikan agama Islam, ada yang melihat dalam perspektif berbeda, namun pada dasarnya antara pendidikan Islam dan pendidikan agama Islam mempunyai kandungan arti yang sama yaitu: pertama, adanya usaha dan proses untuk penanaman (pendidikan) secara kontinue; kedua, adanya hubungan timbal balik antara guru kepada siswa, orang dewasa kepada anak-anak; dan ketiga, al-akhlaq al-karimah sebagai titik akhir tujuan. ${ }^{2}$ Merujuk pada deskripsi tersebut dan dikait dengan konsep tarbiyah, ta'lim dan ta'dib, menegaskan bahwa tujuan akhir dari pendidikan Islam adalah pengembangan potensi dan kompetensi manusia sebagai entitas kosmopolitan berproses sebagai insan kamil yang membawa rahmatan li al'alamin dan uswatun hasanah sebagai wujud perannya sebagai khalifah fi al-ardh. Orientasi tersebut harus didukung oleh pendidikan Islam sebagai sebuah lembaga yang fokus terhadap pendidikan dan pembelajaran untuk menanamkan karakter jujur, tanggung jawab, cerdas dan berintegritas atau disebut dengan istilah prophetic character. ${ }^{3}$ Konsep ini selaras dengan pendidikan Islam sebagai mata pelajaran sesuai

\footnotetext{
${ }^{1}$ Yusef Waghid, "Islamic Education and Cosmopolitanism: A Philosophical Interlude," Studies in Philosophy and Education, 2014, https://doi.org/10.1007/s11217-013-9390-3.

${ }^{2}$ Abdul Rahman, "Pendidikan Agama Islam dan Pendidikan Islam - Tinjauan Epistemologi dan Isi-Materi, Jurnal Eksis, Vol. 8, No. 1, Maret 2012: 2001-2181. p. 2052-2059

${ }^{3}$ Tobroni, "Prophetic Character Transformation for Development of Peace Culture in the School in Indonesia," Journal of Education and Practice, 2014.
} 
dengan semangat UU Sisdiknas No. 20 tahun 2003, bahwa pendidikan agama Islam bukan hanya tentang iman, kesalehan dan akhlak mulia sebagai landasan keagamaan, tetapi juga untuk integrasi aspek kognitif, afektif dan psikomotirik yang membutuhkan kemampuan paripurna pendidik dalam implementasi pembelajarannya. ${ }^{4}$

Problem solving terhadap problematika pendidikan Islam harus mampu masuk pada ranah ontologi, epistemologi dan aksiologi. Problem ontologi pendidikan Islam berkaitan dengan erat dengan tiga maslah, yaitu: pertama, foundation problems yang menyangkut religious and philosophic foundational problems, empiric foundational; kedua, structural problems; dan ketiga, operational problem berkaitan dengan hubungan interaktif komponen pendidikan Islam. Problem pada ranah epistemologi, berkaitan dengan prespektif terhadap pendidikan Islam yang tradisional-konservatif serta proses pengajaran yang bersifat statis indoktrinatif-doktriner, dan secara aksiologi sebagai the theory of value, problem pendidikan Islam terletak pada muatan nilai spiritual dikesampingkan daripada nilai non spiritual.

Tantangan pendidikan Islam di era globalisasi dengan disruption eranya, menjadi momentum dan titik pijak dalam mengembangkan dan membangun pendidikan Islam yang kompetitif. Pendidikan Islam harus mampu bukan saja sebagai alterntif tetapi menjadi pilihan utama masyarakat. Tantangan globalisasi dengan berbagai derivasinya hendaknya mampu dijawab oleh pendidikan Islam. Kemunculan globalisasi sebagai dinamisator, menuntut kemampuan dalam menakar arusnya sehingga reformasi yang dilakukan tidak menghilangkan entitas dan identitas pendidikan Islam itu sendiri. ${ }^{5}$ Reformasi kurikulum dapat dijadikan alternatif solusi dalam menjawab tiga tantangan globalisasi berkaitan erat dengan kemajuan iptek, demokratisasi dan dekadensi moral. ${ }^{6}$ Reformasi kurikulum pendidikan Islam sebagai sebuah jawaban, dalam tataran implementasinya, harus mampu mensinergikan dan mentransformasi nilai-nilai agama, membimbing siswa kepribadian dan akhlak mulia.

Proses penanaman kepribadian dan akhlak mulia dalam pendidikan saat ini menjadi tema sentral dengan istilah pendidikan karakter. Popularitas paradigma

\footnotetext{
${ }^{4}$ Imam Mawardi, "PENDIDIKAN AGAMA ISLAM (PAI) DAN KARAKTERISTIKNYA," Jurnal Ilmu Tarbiyah At-Tajdid Volume 2, no. Nomor 2 (2013).

${ }^{5} \mathrm{M}$ Ihsan Dacholfany, "REFORMASI PENDIDIKAN ISLAM DALAM MENGHADAPI ERA GLOBALISASI: Sebuah Tantangan Dan Harapan," Akademika, 2015.

${ }^{6}$ Mawardi Pewangi, "TANTANGAN PENDIDIKAN ISLAM DI ERA GLOBALISASI," Tarbawi, 2017, https://doi.org/10.1021/ef000272n.
} 
Bahar Agus Setiawan, Benny Prasetiya, Sofyan Rofi: Implementasi Tasawuf dalam Pendidikan Agama Islam: Independensi, Dialog, dan Integrasi

pendidikan karakter tidak lepas dari realita dan fenomena yang terjadi di masyarakat dengan fakta distrust terhadap proses pendidikan yang berlangsung. Fakta distrust bukan terhadap tingkat intelektualitasnya, namun pada kualitas sumber daya manusia. ${ }^{7}$ Pendidikan karakter di Indonesia merupakan bagian dari gerakan masif di seluruh dunia, menemukan popularitasnya pada tahun 2010-an setelah terjadinya sarasehan nasional. Fakta ini merupakan tindak lanjut pada tahun 2009 Depdikbud telah mengidentifikasi 49 kualiats karakter yang kemudian oleh Kemendiknas diringkas menjadi sembilan pilar pendidikan karakter. ${ }^{8}$ Pendidikan karakter pada tataran implementasinya berkaitan dengan tiga elemen, yaitu: pemahaman, pembiasaan dan keteladanan yang menjadi satu kesatuan utuh yang saling terintegrasi. ${ }^{9}$

Merujuk pada deskripsi di atas, maka pada dasarnya dapat dipahami bahwa dalam teminologi pendidikan Islam adalah pendidikan akhlak yang didasarkan pada alqur'an dan sunnah yang dalam proses pelaksanaannya disesuaikan dengan perkembangan dan pembentukan karakter anak. ${ }^{10}$ Konsep ini sejalan dengan arah pendidikan Islam dalam konsepsi al-Qur`an yang tertera antara lain: Q.S. Al-Fath (48): 29, Q.S. Al-Hajj (22): 41, dan Q.S. Al-Zariyat (51): 56. ${ }^{11}$ Pendidikan akhlak dalam pendidikan Islam dianggap tertinggal dengan konsep pendidikan karakter, dikarenakan masih dianggap bersifat stagnan, tanpa konversi dan perlu adaptasi serta inovasi mencakup beberapa hal yang salah satunya adalah model pembelajaran. ${ }^{12}$ Penegasan atas deskripsi tersebut, dalam konteks modernisme pendidikan Islam, pendidikan akhlak membutuhkan pembaharuan sistem, metode dan kurikulum untuk mendukung pembangunan karakater yang merupakan proses transformasi living value. ${ }^{13}$ Pendeknya, dalam mewujudkan character building/pendidikan akhlak, agama merupakan asas

\footnotetext{
${ }^{7}$ Azkia Muharom Albantani and Ach Wildan Al Faizi, "Pendidikan Karakter Menuju Indonesia Emas 2045," in Seminar Nasional Program Studi Pendidikan Guru Madrasah Ibtidaiyah (PGMI), 2015.

${ }^{8}$ Siti Fatimah, "Formalisme Pendidikan Karakter Di Indonesia: Telaah Pendidikan Islam," Ilmu Pendidikan IAIN Raden Intan Lampung, 2012, https://doi.org/https://doi.org/10.15575/jpi.v27i1.499.

${ }^{9}$ Taufik, "Pendidikan Karakter Di Sekolah: Pemahaman, Metode Penerapan, Dan Peranan Tiga Elemen,” Jurnal Ilmu Pendidikan, 2014, https://doi.org/10.1021/nl0714334.

${ }^{10}$ Diah Novita Fardani, "PENDIDIKAN KARAKTER DALAM PERSPEKTIF ISLAM UNTUK SISWA SD: Solusi Bagi Problematika Pendidikan Sekolah Dasar Islam Terpadu Di Era Modern," Journal AL-MUDARRIS, 2018, https://doi.org/10.32478/al-mudarris.v1i2.174.

${ }^{11}$ Mazro'atus Sa'adah, "ARAH PENDIDIKAN ISLAM DALAM AL-QUR'AN," At-Tajdid: Jurnal Ilmu Tarbiyah, 2014.

${ }^{12}$ Imam Sutomo, "Modification of Character Education into Akhlaq Education for the Global Community Life," IJIMS, Indonesian Journal of Islam and Muslim Societies, 2014, https://doi.org/10.18326/ijims.v4i2.291-316.

${ }^{13}$ Najwa Mu'minah, "Character Building Dalam Konsep Pendidikan Imam Zarkasyi Ditinjau Dari Filsafat Moral Ibnu Miskawaih,” Jurnal Filsafat, 2015.
} 
fundamental sebagai landasan dalam mencapai tujuan pendidikan secara universal baik dari nilai etika maupun estetika. Pandangan ini muncul dikarenakan adanya world view yang berkembang bahwa nilai intelektulitas lebih penting daripada nilai spiritualitas. ${ }^{14}$ Bukti kongkrit bahwa sebenarnya nilai spiritual lebih memiliki domain dalam proses pendidikan adalah istilah spiritual quetion (SQ) dalam perkembangannya menjadi intelektual emotional spiritual question (IESQ). ${ }^{15}$

Spiritualitas sudah menjadi corak, label dan identitas baru dalam berbagai tema kajian, penelitian dan pendidikan. Paradigma spiritualitas sendiri terdiri atas tiga pola dasar yaitu spiritualitas psikologi manusia, alam dan agama. Dua pola pertama yaitu spiritualitas psikologi manusia dan alam yang merupakan hakikat sains bahwa pusat energi adalah manusia dan alam (antropho dan natural centre) yang bersifat terbatas sedangkan spiritulitas agama sebagai jalan keluar dalam mengatasi keterbatasan tersebut. Proses penanaman spiritulitas agama diperlukan metode dan strategi khusus agar mudah dimengerti dan diaktualisasikan.

Istilah spiritualitas dalam sejarah peradaban Islam lebih populer dikenal dengan istilah tasawuf atau sufisme. Penekanan dimensi "rasa" atau aspek bathiniah daripada "rasio" menjadi indikator utama tasawuf. Meskipun indikator ini dianggap berseberangan dengan nilai-nilai masyarakat modern, namun menjadi problem solving untuk mengatasi berbagai tekanan dari sifat-sifat hedonis, materialis dan lainnya, ${ }^{16}$ sebagai bentuk ancaman terhadap manusia yang bersifat katrastofal. ${ }^{17}$ Tasawuf menjadi jalan keluar dalam mengahadapi kondisi dan situasi tersebut apabila disandarkan terhadap definisi dan tujuannya sebagai suatu pengetahuan yang menelaah seluk beluk hubungan manusia dengan Sang Khaliq, sebagai proses pembersihan jiwa, mentaqarrubkan diri kepada Allah, membersihkan sifat negatif dengan ibadah, menghias diri dengan akhlaqul karimah, mengejar eskatologis daripada materialis dan lainnya. $^{18}$

\footnotetext{
${ }^{14}$ Mashudi Mashudi, "APLIKASI TASAWUF DALAM DUNIA PENDIDIKAN MODERN," Jurnal Paradigma Institut, 2015.

${ }^{15}$ Nur Muslimin, "PENDIDIKAN AGAMA ISLAM BERBASIS IQ, EQ, SQ DAN CQ," Kabilah, 2016.

${ }^{16}$ Tri Astutik Haryati and Mohammad Kosim, "TASAWUF DAN TANTANGAN MODERNITAS," ULUMUNA, 2010.

${ }^{17}$ Ahmad Sidqi, "WAJAH TASAWUF DI ERA MODERN: Antara Tantangan Dan Jawaban," Epistemé: Jurnal Pengembangan Ilmu Keislaman, 2015, https://doi.org/10.21274/epis.2015.10.1.1-28.

${ }^{18}$ Mashudi, "APLIKASI TASAWUF DALAM DUNIA PENDIDIKAN MODERN."
} 
Paradigma tasaswuf yang ideal, akan menjadi hal yang sangat bermakna apabila dapat diimplementasikan dalam dunia pendidikan khususnya berkaitan dengan proses pendidikan agama Islam. Terlepas dari perdebatan yang terjadi dalam dunia tasawuf, ada dua macam tipologi tasawuf yaitu tasawuf akhlaqi dan tasawuf falsafi yang dalam perkembangan keilmuan muncul istilah-istilah baru seperti tasawuf konvensional, tasawuf tradisional, tasawuf sainstifik, taswuf transformatf dan lainnya. Tasawuf yang dimunculkan sebagai penawar problematika pendidikan Islam yang sedang dihadapi. Cita-cita ideal terbentukknya insan kamil dari proses pendidikan agama Islam dapat diwujudkan dengan menjadikan tasawuf sebagai sebuah metode dan strategi pembelajaran. Merujuk pada kalimat tersebut, pertanyaan mendasar yang timbul sebagai rumusan masalah adalah bagaimana implementasi tasawuf dalam pendidikan agama Islam. Tujuan penelitian ini untuk mengatahui implementasi tasawuf dalam pendidikan agama Islam.

\section{B. Perkembangan dan Pemikiran Tasawuf}

Istilah tasawuf dalam tradisi studi Islam juga disebut dengan istilah lainnya seperti sufime dan mistisisme. Terlepas dari berbagai perdebatan yang ada istilah-istilah tersebut merupakan istilah yang sudah mapan dan formal dalam kajian studi Islam. Istilah sufisme atau tasawuf merupakan istilah yang identik dan dapat dikatakan hanya ada dalam Islam.

Tinjauan etimologi, tasawuf mempunyai makna asal dari tashawwafa yatashawwafu, yang artinya (menjadi) berbulu banyak. Landasan pengertian ini didasarkan pada asal katanya yaitu shaafa - yashuufu menjadi shaufan bentuk mashdar yang artinya berbulu banyak. Istilah ini kemudian dikenal dengan kata "shufi" yang menjadi ciri khasnya adalah pada pakaian yang terbuat dari kain wol (bulu domba). Pemakian kain wol ini merupakan identitas dan simbol tasawuf untuk mencerminkan sifat kesederhanaan. Pengertian istilah "shuffah" yang berarti serambi masjid, didasari oleh para sahabat muhajirin yang hidup di Masjid Nabawi dengan dengan Rasulullah yang hidup zuhud dan konsentrasi ibadah. Perspektif linguistik (bahasa) definisi tersebut memberikan pemahaman bahwa keserhanaan, bijaksana, memelihara kesucian, taat ibadah merupakan gambaran hakikat dari akhlak yang mulai. 
Perspektif terminologi, banyak sekali definisi tentang tasawuf mulai al-Junaidi al-Baghdadi, al-Ghazali, al-Nawawi, al-Kurdi, 'Abd al-Qadir al-Jailani, yang dari beberapa pengertian tersebut dapat diambil definisi sederhana bahwa taswuf merupakan penyucian jiwa dan menjauhi hawa nafsu yang didasari dengan ilmu yang tercermin dalam amal untuk mendekatkan diri dan mencapai karunia Allah. Tasawuf merupakan spiritualitas Islam yang bertujuan membangun kesalehan dan kesempurnaan kebajikan manusia yang sesuai dengan al-Qur`an, sinergi antara yang bersifat etis dan teologis. ${ }^{19}$ Tasawuf sebagai doktrin penyucian jiwa menuju Allah melahirkan sufisme sebagai aktualisasinya, berkaitan dengan 3 bentuk yaitu penyucian jiwa, berperilaku sufi dan gerakan sufi.

Perspektif universal tentang sufisme, yaitu berakar pada wahyu Islam yang menghasilkan etika yang berifat dinamis bukan hanya dipelajari mampu memberikan kontribusi yang integral dalam pembentukan moral masyarakat Islam. ${ }^{20}$ Perkembangan konsep spiritualitas yang identik dengan sufisme telah dijadikan dasar dalam menentukan kesehatan mental seseorang, bukan lagi hanya wilayah domain agama. ${ }^{21}$

Perkembangan pemikiran tasawuf di era modern menunjukkan dinamika yang progresif dan bersifat masif. Istilah-istilah baru yang berkaitan dengan tasawuf lahir di era modern ini mulai tasawuf tradisional, tasawuf konvensional, tasawuf transformatif, tasawuf saintifik dan lainnya memberikan gambaran nyata bahwa tasawuf sudah melintasi batas-batas yang tidak hanya berkaitan dengan agama an sich. Tasawuf dan perkembangannya sudah mampu melahirkan rekonstruksi konseptual sehingga menjadi paradigma progresif dalam kehidupan manusia modern. Telaah baru konsep-konsep dalam dunia tasawuf mendorongnya menjadi keilmuan yang bersifat transformatif yang menjadikannya tidak kaku tetapi cenderung elastis dan fleksible. Tokoh modernis Islam seperti Hamka mampu mewarnai pemikiran baru dalam dunia tasawuf dalam konteks keIndonesiaan. Pemikiran Hamka adalah menghadirkan tasawuf tanpa tarekat, mendorong etos rasionalitas dan tanggung jawab untuk penanaman kabajikan spiritual sufi dalam kehidupan sehari-hari. Konotasi negatif terhadap konsep-konsep tasawuf tekah mengalami perkembangan makna dan istilah. Istilah zuhud yang dianggap sebagai

\footnotetext{
${ }^{19}$ Paul L. Heck, "Sufism? What Is It Exactly?," Religion Compass, 2007, https://doi.org/10.1111/j.1749-8171.2006.00011.x.

${ }^{20}$ Paul L. Heck, "Mysticism as Morality: The Case of Sufism," Journal of Religious Ethics, 2006, https://doi.org/10.1111/j.1467-9795.2006.00268.x.

${ }^{21}$ Shaque Nizamie, MohammadZia Ul Haq Katshu, and NA Uvais, "Sufism and Mental Health," Indian Journal of Psychiatry, 2013, https://doi.org/10.4103/0019-5545.105535.
} 
penyebab kemunduran Islam, di era modernis telah mengalami penafsiran baru. Esensi makna zuhud pada awal perkembangn tasawuf sebagai konsep meninggalkan dunia, zuhud di era modern ditafsirkan sebagai sikap meninggalkan sesuatu yang mengalihkan perhatian kepada Allah sehingga menuntut pelaku zuhud yaitu zahid esensinya manusia yang mampu bersikap integratif dan inklusif. Pemaknaan ini lebih melihat zuhud pada tataran yang benar-benar bersifat positif dan fungsional.

Deskripsi di atas menjelaskan bahwa tipologi tasawuf di era modern secara garis besar dapat dikategorisasikan ke dalam dua model yaitu tasawuf tradisional/ konvensional dan tasawuf modern/transformatif. Kategorisasi dirujuk pada karateristik model implementasinya, pada tasawuf tradisional/konvensional cenderung pada pemahaman konsep-konsep tasawuf bersifat pasif, pada tasawuf modern/transformatif lebih pada dimensi positif dan aktif.

Merujuk pada konteks tersebut di atas, tasawuf transformatif/modern menjadi konsentrasi telaah seiring dengan perkembangan konseptual tasawuf di era modern. Kegagalan manusia dalam memposisikan dirinya sesuai dengan fitrah adalah ketidak mampuannya dalam memilih sikap (akhlak) dalam berinteraksi dengan semesta. Pencarian dan pengenalan terhadap diri (inward looking) menjadi sebuah keniscayaan didasarkan pada 2 aspek yaitu ultimate concern (memahami Allah) dan mengenal diri mampu memahami apa yang harus dilakukan dan bagaimana harus bersikap (akhlak). Deskripsi tersebut merupakan fakta bahwa dalam probelamtika kehidupan, manusia belum bisa menempatkan dirinya secara tepat dan benar. Lima tipologi tasawuf transformatif, antara lain: pertama, visi keilahian (tauhid dan ma'rifat Allah); kedua, sinergisitas antara akal dan wahyu; ketiga, dunia dalam ekatologi Islam; keempat, alakhlaq al-karimah; dan kelima, amal soleh berdimensi Islam. Keinginan dari taswuf transformatif adalah mendidik manusia untuk memiliki kesadaran sosial yang bersifat transpersonal dalam kohesi sosial yang kuat yang dibangun oleh nilai-nilai transendental yang dimiliki oleh manusia.

Pengertian tasawuf tradisional seperti yang telah disinggung di atas, lebih memahami konsep tasawuf dalam tataran yang bersifat pasif. Menegasikan dan menghilangkan kehidupan dunia untuk lebih fokus dan totalitas dalam pengabdian kepada Ilahi merupakan ciri khas yang melekat pada tasawuf tradisional. Konseptualisasi tasawuf konvensional/tradisional lebih kearah model tasawuf falsafi dalam terminologi Hamka tasawuf konvensional/tradisional terjebak dalam tarekat. 


\section{Implementasi Tasawuf dalam Pendidikan Agama Islam}

Krisis multi dimensi yang dialami masyarakat modern membutuhkan jalan keluar yang tidak bersifat peyoratif, memberi obat panawar namun sekaligus sebagai racun yang mematikan. Gagasan jalan keluar yang dipilih harus mampu dianalisis secara rasional dan spiritual sehingga memberikan solusi yang bersifat objektif dan komprehensif. Perkembangan dunia tasawuf dengan berbagai ragamnya, memberikan arah dan pandangan baru dalam proses implementasi Pendidikan Agama Islam (PAI) sebagai salah satu mata pelajaran yang wajib ada dalam struktur kurikulum dari tingkat usia dini hingga perguruan tinggi.

Pendidikan agama Islam merupakan landasan fundamental dalam membentuk etika dan estetika manusia. Makna pendidikan dalam terminologi Islam bukan hanya pada konsep eskatologis saja tetapi merupakan proses pengembangan dan pembentukan manusia yang dilandasi tauhid/mengesakan Allah. Pengembanagn potensi dan kompetensi peserta didik secara komprehensif dan universal namun tetap berlandaskan semangat ketauhidan/keilahian. ${ }^{22}$

Pelaksanaan pendidikan agama Islam di sekolah pada khususnya tentu tidak akan lepas dari kebutuhan konsep, teknik, metode, strategi dan model yang sesuai agar efektivitas dan efisiensi pembelajaran dapat diwujudkan. Pembelajaran sebagai ruh proses pendidikan merupakan komponen yang tidak bisa dianggap remeh karena sebaik apapun kurikulum, tujuan pendidikan dan lainnya tanpa proses pembelajaran tidak dapat disebut sebagai pendidikan. Inovasi-inovasi dalam bidang implementasi pembelajaran terus dilakukan untuk menghasilkan kualitas pembelajaran yang paripurna. Perubahan paradigma teacher centered ke arah student centered leraning sebagai bagian untuk menjadikan implementasi pembelajaran menjadi lebih aktif, inovatif, efektif dan menyenangkan yang populer disebut dengan istilah PAIKEM.

Pendidikan agama Islam sebagai sebuah mata pelajaran harus mampu menselaraskan dengan perkembangan dan inovasi dalam bidang pembelajaran. Menjadikan pembelajaran pendidikan agama Islam sebagai proses yang dinamis, kreatif, inovatif dan menyenangkan menjadi sebuah keniscayaan yang harus mampu diwujudkan. Tujuan pendidikan agama Islam sebagai upaya untuk menguatkan, pemahaman, pengahayatan dan pengalaman siswa atas keimanan, bertakwa dan

${ }^{22}$ Muh Mustakim, "ONTOLOGI PENDIDIKAN ISLAM (Hakikat Pendidikan Dalam Perspektif Islam)," At-Tajdid : Jurnal Ilmu Tarbiyah, 2012. 
berkahlak mulia dalam kehidupan manusia secara universal. Pendidikan agama Islam adalah proses pembelajaran untuk mengarahkan manusia kepada akhlak mulia/al-akhlaq al-karimah. Materi pembelajaran pendidikan agama Islam secara umum meliputi akidah, akhlak dan muamalah/syariah. Materi bahasan pendidikan agama Islam, pengembangannya dilakukan dengan tiga konteks pendekatan yaitu: hubungan manusia dengan Allah, manusia dengan manusia dan manusia dengan alam.

Perwujudan pengembangan pembelajaran pendidikan agama Islam dapat dipahami dalam dua aspek yaitu secara kuantitatif dan kualitatif. Pelajaran pendidikan agama Islam yang secara kuantitatif hanya dua jam pelajaran harus mampu memberikan pengaruh baik di dalam maupun di luar sekolah. Adapun secara kualitatif, pendidikan agama Islam mampu menampilkan pembelajaran yang bermutu, sejalan dengan nilai idealisme islami dan mampu merespon dan mengantisipasi berbagai problematika kehidupan. Pemikrian kreatif dan inovatif pengembangan pembelajaran pendidikan agama Islam merujuk pada prinsip perubahan (change), pertumbuhan (growth), pembaharuan (reform) dan terus menerus (continuity). Proses ini dalam manajemen mutu pendidikan dikenal dengan istilah continues quality improvement, dalam konteks pendidikan agama Islam tentu terkait dengan implementasi pembelajaran. Pengembangan di samping mengedepankan sensivitas pada mainstream, di sisi lain juga harus mempertimbangkan fondasinya, sehinga proses tersebut tidak kehilangan spirit dan ruh Islami. ${ }^{23}$ Pengembangan implementasi pembelajaran pendidikan agama Islam harus bisa merubah paradigma pengetahuan agama yang bersifat kognitif menjadi "makna" dan "nilai." Pendidikan agama Islam bukan hanya tataran knowing dan doing tetapi secara aktif mampu membentuk peserta didik pada aspek being.

Indikator-indikator implementasi pendidikan agama Islam apabila dianalisis lebih mendalam orientasinya sejalan dengan keinginan tasawuf, sehingga di era modern ini sudah saatnya proses Islamisasi ilmu pengetahuan khususunya dalam dunia pendidikan bukan hanya pada sebatas ayatisasi an sich yang cenderung terjebak pada formalis daripada esensialisnya. Keinginan untuk pengintegrasian tasawuf dalam implementasi pendidikan agama Islam harus benar-benar digali secara komprehensif. Tulisan ini pada dasarnya akan mencoba menyoroti tasawuf baik itu tasawuf tradisional/konvensional dan tasawuf modern/trasformatif dalam implementasi 2014.

\footnotetext{
${ }^{23}$ Su'dadah, "Kedudukan Dan Tujuan Pendidikan Islam Di Sekolah,” Jurnal Kependidikan,
} 
pendidikan agama Islam. Titik pijak yang digunakan dalam menelaah bahasan tersebut akan merujuk pada ide konsep Ian G. Barbour tentang empat hubungan sains dan agama yaitu konflik, indenpendesi, dialog dan integarsi. ${ }^{24}$ Sains pada bahasan ini dihubungkan dengan implementasi pendidikan agama Islam dalam ranah pembelajaran sedangkan agama adalah kedudukan tasawuf baik tradisional/konvesional dan modern/ transformatif sebagai dimensi yang bersifat esoteris. Konsep yang digunakan sebagai landasan adalah taksonomi Blom berkaitan dengan tiga ranah, yaitu kognitif, afektif dan psikomotorik.

\section{Konflik}

Sudut padang konflik dalam terminologi ini adalah adanya ketidak hamronisan, kesesuaian dan keselarasan tujuan tasawuf dengan implementasi pendidikan pada umumnya dan pendidikan agama Islam pada khususnya. Indikator utama implementasi pendidikan agama Islam masih terjebak pada tataran kognitif sebagai wujud kongkrit kesuksesan prosesnya. Aspek kognitif yang merupakan bagian dari taksonomi Bloom, merujuk pada enam aspek sebagai indikatornya yaitu pengetahuan dan ingatan, pemahaman, aplikasi, analisis, sistesis dan evaluasi. ${ }^{25}$ Berkaitan dengan hal tersebut, kesuksesan proses impelmentasi pendidikan masih terjebak pada ranah yang bersifat formalis yaitu kemampuan peserta didik dalam menjawab, menganalisis yang lebih menekankan pada kemampuan intelektual belum pada tataran spiritual. Kesuksesan proses implementasi pendidikan yang lebih populer disebut dengan prestasi belajar hanya disimbolkan dengan capaian nilai yang tertera pada buku raport siswa. Padahal dalam proses perwujudan prestasi belajar merupakan hasil dari kolaborasi proses dari raw input, enviromental input, instrumental input dalam membentuk learning teaching process. $^{26}$

Sedangkan pada tasawuf baik tradisional dan transformatif dalam implementasi pendidikan agama Islam, prestasi belajar yang menjadi indikator utamanya adalah ranah afektif yang berkaitan dengan pengenalan (ingin menerima, sadar akan adanya sesuatu), merespon (aktif berpartisipasi), penghargaan (menerima nilai-nilai), pengorganisasian

\footnotetext{
${ }^{24}$ Waston, "HUBUNGAN SAINS DAN AGAMA: Refleksi Filosofis Atas Pemikiran Ian G. Barbour," PROFETIKA, Jurnal Studi Islam, https://doi.org/https://doi.org/10.23917/profetika.v15i1.1968.

${ }^{25}$ Nana Sudjana, Dasar-dasar Proses Belajar Mengajar (Bandung : Sinar Baru Algetindo, 2010),

${ }^{26}$ Saiful Bahri Djamarah, Strategi Belajar Mengajar (Jakarta: Rineka Cipta. Cet. Kelima, 2013), 
(menghubungkan nilai-nilai yang dipercayainya) dan pengamalan (menjadikan nilainilai sebagai bagian dari pola hidupnya). Di sisi lain penggunaan tasawuf dalam proses implementasi pendidikan Islam dapat dianggap menyimpang dikarenakan porsesnya yang cenderung kontradiksi dengan konsep implementasi pembelajaran yang sudah mapan. Pembelajaran dengan model tasawuf lebih pada teacher centered learning sedangkan paradigma yang sedang berkembang saat ini pada pembelajaran lebih pada student centered learning.

\section{Independensi}

Secara etimologi makna independensi adalah kondisi, keadaan, posisi di mana tidak terikat dengan pihak manapun. Perspektif sebagai model pembelajaran dalam implementasi pendidikan agama Islam lebih banyak pada tataran pemahaman pendidikan agama Islam dalam kerangka spiritual dan material pembelajaran. Meskipun pada tataran implementasi stresing point tujuan akhirnya sama, namun paradigma pendidikan karakter sebagai paradigma pendidikan saat ini melihat antara karakter dan materi pembelajaran pendidikan agama Islam masuk pada ranah yang berbeda. Namun pada dasarnya antara tasawuf sebagai sebuah model pembelajaran dan pendidikan agama Islam lebih pada ranah materi pembelajaran harus terjadi berusaha menginterpretasikan ragam hal itu dalam pandangan yang lebih dialektis dan komplementer.

\section{Dialog}

Perspektif ini menawarkan hubungan tasawuf dan implementasi pendidikan agama Islam dengan interaksi yang lebih bersifat konstruktif dariapda pandangan konflik atau independensi. Meskipun memiliki tujuan yang sama baik pendidikan agama Islam dalam konteks meningkatkan kecerdasan spiritual dan pendidikan agama Islam sebagai proses meningkatkan kecerdasan intelektual dalam artian nilai-nilai agama Islam hanya sebatas pada tataran evaluasi kognitif harus terjadi proses dialogis. Tasawuf dengan kekuatan proses spiritualnya dan pendidikan agama Islam sebagai materi pembelajaran harus disejajarkan secara konseptual yang menawarkan interaksi dengan tetap memeprtahankan integritas masing-masing.

\section{Integrasi}

Analisis pada wilayah integrasi dasar utama yang digunakan adalah spider web ala Amin Abdullah. Teori jaring laba-laba (spider web) yang digagas oleh Amin 
Abdullah berkaitan dengan horison keilmuan Islam, bukan saja bertujuan untuk mengembangkan kerangka ilmuilmu dasar keislaman yang bersifat normatif, tetapi juga ingin mengintegrasikannya dengan ilmu sekular yang bersifat empiris-rasional. Pada aspek inilah daya tarik pemikiran Amin Abdullah, di mana ia mampu merumuskan epistemologi keilmuan yang dapat meramu bermacam-macam ilmu sehingga jelas apa esensi masing-masing disiplin ilmu dan bagaimana cara dan strategi untuk mengembangkannya.

Spider web adalah suatu strategi pembelajaran yang sengaja dirancang untuk memudahkan transfer pengetahuan dan pengalaman kepada anak didik. Umumnya strategi ini diterapkan dalam sekolah atau pembelajaran outbound. Pada konteks ini, metode spider web menawarkan strategi pembelajaran yang mengintegrasikan suatu tema ke dalam semua mata pelajaran. Dalam kegiatan belajar outbound (sekolah alam), semua objek pembelajaran di alam dapat dikaitkan dalam satu tema yang nantinya akan dijabarkan dalam mata pelajaran yang akan digunakan, sedangkan dalam pembelajaran konseptual, metode ini menghasilkan suatu peta konsep. Ciri terpenting dari peta konsep spider web itu adalah tidak menurut hirarki, kecuali berada dalam suatu kategori; dan kategorinya tidak parallel. Spider web adalah suatu strategi pembelajaran yang sengaja dirancang untuk memudahkan transfer pengetahuan dan pengalaman kepada anak didik. Umumnya strategi ini diterapkan dalam sekolah atau pembelajaran outbound. Pada konteks ini, metode spider web menawarkan strategi pembelajaran yang mengintegrasikan suatu tema ke dalam semua mata pelajaran. Dalam kegiatan belajar outbound (sekolah alam), semua objek pembelajaran di alam dapat dikaitkan dalam satu tema yang nantinya akan dijabarkan dalam mata pelajaran yang akan digunakan, sedangkan dalam pembelajaran konseptual, metode ini menghasilkan suatu peta konsep. Ciri terpenting dari peta konsep spider web itu adalah tidak menurut hirarki, kecuali berada dalam suatu kategori; dan kategorinya tidak parallel. ${ }^{27}$

Merujuk deskripsi spider web ala Amin Abdullah di atas, dihubungkan dengan konsep tasawuf tradisional dan tasawuf transfomatif dalam implementasi pembelajaran perlu dilakukan kajian dan telaah yang bersifat sistematis bukan hanya pada tataran teknik dan strategi pelaksanaannya tetapi juga pada aspek sistem evaluasi pendidikan agama Islam yang mampu menjebatani prestasi pembelajaran yang bercorak spiritual dengan indikator-indikator yang tepat dan jelas.

\footnotetext{
${ }^{27}$ Parluhutan Siregar, "Integrasi Ilmu-Ilmu Keislaman dalam Perspektif M. AMin Abdullah," Jurnal Miqot, Vol. XXXVIII, No. 2, Juli-Desember 2014. p 335-354.
} 
Bahar Agus Setiawan, Benny Prasetiya, Sofyan Rofi: Implementasi Tasawuf dalam Pendidikan Agama Islam: Independensi, Dialog, dan Integrasi

\section{Kesimpulan}

Peta konsep tasawuf tradisional lebih bersifat pasif sedangkan tasawuf transformatif lebih bersifat aktif. Implementasi pembelajaran pendidikan agama Islam dengan dua konsep tasawuf tersebut dapat ditipologikan ke dalam empat dimensi yaitu konflik, independensi, dialog dan integrasi. Telaah terhadap empat tipologi tersebut dalam implementasi pendidikan agama Islam dapat dianalsis dari teori Bloom berkaitan dengan aspek kognitif, afektif dan psikomotorik serta pendekatan paradigma pembelajaran antara teacher centered learning dan student centered learning.

\section{E. Daftar Pustaka}

Albantani, Azkia Muharom, and Ach Wildan Al Faizi. "Pendidikan Karakter Menuju Indonesia Emas 2045." In Seminar Nasional Program Studi Pendidikan Guru Madrasah Ibtidaiyah (PGMI), 2015.

Dacholfany, $M$ Ihsan. "REFORMASI PENDIDIKAN ISLAM DALAM MENGHADAPI ERA GLOBALISASI: Sebuah Tantangan Dan Harapan." Akademika, 2015.

Djamarah, Saiful Bahri. Strategi Belajar Mengajar. Jakarta: Rineka Cipta. Cet. Kelima, 2013

Fardani, Diah Novita. "PENDIDIKAN KARAKTER DALAM PERSPEKTIF ISLAM UNTUK SISWA SD : Solusi Bagi Problematika Pendidikan Sekolah Dasar Islam Terpadu Di Era Modern.” Journal AL-MUDARRIS, 2018. https://doi.org/10.32478/al-mudarris.v1i2.174.

Fatimah, Siti. "Formalisme Pendidikan Karakter Di Indonesia: Telaah Pendidikan Islam." Ilmu Pendidikan IAIN Raden Intan Lampung, 2012. https://doi.org/https://doi.org/10.15575/jpi.v27i1.499.

Haryati, Tri Astutik, and Mohammad Kosim. "TASAWUF DAN TANTANGAN MODERNITAS." ULUMUNA, 2010.

Heck, Paul L. "Mysticism as Morality: The Case of Sufism." Journal of Religious Ethics, 2006. https://doi.org/10.1111/j.1467-9795.2006.00268.x.

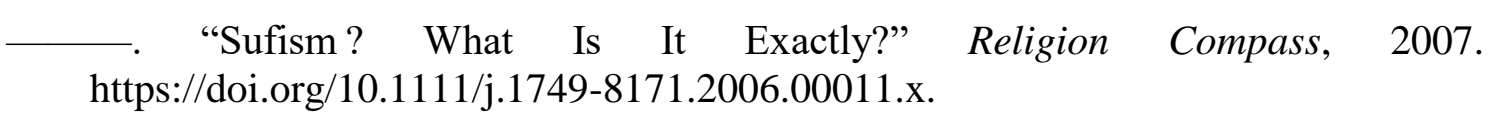

Mashudi, Mashudi. "APLIKASI TASAWUF DALAM DUNIA PENDIDIKAN MODERN.” Jurnal Paradigma Institut, 2015.

Mawardi, Imam. "PENDIDIKAN AGAMA ISLAM (PAI) DAN KARAKTERISTIKNYA.” Jurnal Ilmu Tarbiyah At-Tajdid Volume 2, no. Nomor 2 (2013).

Mu'minah, Najwa. “Character Building Dalam Konsep Pendidikan Imam Zarkasyi Ditinjau Dari Filsafat Moral Ibnu Miskawaih.” Jurnal Filsafat, 2015.

Muslimin, Nur. "PENDIDIKAN AGAMA ISLAM BERBASIS IQ, EQ, SQ DAN CQ." 
Kabilah, 2016.

Mustakim, Muh. "ONTOLOGI PENDIDIKAN ISLAM (Hakikat Pendidikan Dalam Perspektif Islam).” At-Tajdid: Jurnal Ilmu Tarbiyah, 2012.

Nizamie, SHaque, MohammadZia Ul Haq Katshu, and NA Uvais. "Sufism and Mental Health." Indian Journal of Psychiatry, 2013. https://doi.org/10.4103/00195545.105535.

Pewangi, Mawardi. "TANTANGAN PENDIDIKAN ISLAM DI ERA GLOBALISASI.” Tarbawi, 2017. https://doi.org/10.1021/ef000272n.

Rahman, Abdul. "Pendidikan Agama Islam dan Pendidikan Islam - Tinjauan Epistemologi dan Isi-Materi, Jurnal Eksis, Vol. 8, No. 1, Maret 2012: 20012181. p. 2052-2059

Sa'adah, Mazro'atus. "ARAH PENDIDIKAN ISLAM DALAM AL-QUR'AN.” AtTajdid: Jurnal Ilmu Tarbiyah, 2014.

Sidqi, Ahmad. "WAJAH TASAWUF DI ERA MODERN: Antara Tantangan Dan Jawaban.” Epistemé: Jurnal Pengembangan Ilmu Keislaman, 2015. https://doi.org/10.21274/epis.2015.10.1.1-28.

Su'dadah. "Kedudukan Dan Tujuan Pendidikan Islam Di Sekolah." Jurnal Kependidikan, 2014.

Sudjana, Nana. Dasar-dasar Proses Belajar Mengajar. Bandung: Sinar Baru Algetindo, 2010.

Sutomo, Imam. "Modification of Character Education into Akhlaq Education for the Global Community Life." IJIMS, Indonesian Journal of Islam and Muslim Societies, 2014. https://doi.org/10.18326/ijims.v4i2.291-316.

Taufik. "Pendidikan Karakter Di Sekolah: Pemahaman, Metode Penerapan, Dan Peranan Tiga Elemen." Jurnal Ilmu Pendidikan, 2014. https://doi.org/10.1021/n10714334.

Tobroni. "Prophetic Character Transformation for Development of Peace Culture in the School in Indonesia." Journal of Education and Practice, 2014.

Waghid, Yusef. "Islamic Education and Cosmopolitanism: A Philosophical Interlude." Studies in Philosophy and Education, 2014. https://doi.org/10.1007/s11217-0139390-3.

Waston. "HUBUNGAN SAINS DAN AGAMA: Refleksi Filosofis Atas Pemikiran Ian G. Barbour." PROFETIKA, Jurnal Studi Islam, 2014. https://doi.org/https://doi.org/10.23917/profetika.v15i1.1968. 